negative salience effect to a female-content form. The finding of a Sex of P by Sex of $O$ interaction is somewhat tentatively interpreted, since it depends primarily upon the ratings of a single treatment group that responded with higher ratings than did a presumably comparable group in an earlier study. Should this interaction prove reliable, it might reasonably be explained as a function of greater identification and empathy with others of one's own sex. It may be a function, also, of the relative ages of $\mathrm{P}$ and $\mathrm{O}$. Own-sex others were not more favorably rated in the somewhat different type of study by Richey \& Fichter (1969) in which college students judged other college students. In that study, it was suggested that judges might be more lenient toward opposite-sex persons who were their own age rather than older because they would be more likely to be attracted to contemporaries.

The negative salience phenomenon has theoretical implications for theories of information integration in impression formation, at least so far as these concern impressions of character. Neither a summation nor an averaging theory specifically predicts a disproportionate weight of negative information. Empirical studies testing these theories have reported results consistent with the assumption of equal weight of positive and negative information. Differences between previous results and the present findings may be due to the stimuli (narratives vs adjective lists), the restriction of the present descriptions to behaviors with moral-ethical implications, and the use of delayed measures in the present study.

\section{REFERENCES}

CLSLMANO. D. R. Information valence in impression formation. Linpublished doctoral dissertation, St. Louis University, 1968.

KLINGER, E., ALBAUM, A., \& HETHERINGTON, M. Factors influencing the severity of moral judgments. Journal of Social Psychology, 1964, 63, 319-326.

RICHEY, M. H., \& FICHTER, J. J. Sex differences in moralism and punitiveness. Psychonomic Science, 1969, 16, 185-186.

RICHEY, M. H., McCLELLAND, L., \& SHIMKUNAS, A. M. Relative influence of positive and negative information in impression formation and persistence. Joumal of Personality \& Social Psychology, 1967.6, 322-327.

\title{
Learning the rules of categorized free recall
}

\author{
JOSHUA R. GEROW \\ Purdue University, Fort Wayne, Ind. 46805
}

When Ss were presented with six lists of 25 stimulus words such that the only thing the lists had in common was that they were constructed using five words from each of five different categories, the number of words recalled and the average cluster size of responses increased over the six presentations. This increase interacted with the frequency of occurrence of the items used. The results were taken to indicate the development of a general strategy or rule used to advantage by Ss in free-recall experiments.

There seems to be no doubt that Ss make use of interitem associations when recalling a list of words. Words are found to cluster together in recall to the degree that they share common associative relations (Jenkins \& Russell, 1952: Tulving, 1962). It also seems reasonable that there is some organizing process (a rule or strategy) at work in free-recall experiments that transcends simple word-to-word associations (Mandler, 1966: Hudson, 1968). It is possible to consider recall as the result of a generative process that depends upon a set of attributes associated with the to-be-recalled materials (Pollio \& Gerow, 1968: Underwood, 1969). In the case of word associations. one word produces another as an associate because they share common attributes. In the categorical case, items are generated as members of a category because all the elements of the category share attributes with each other and with the category name.

The experiment reported attempted to minimize all opportunities to take advantage of interitem associates and to make it possible to respond to categorical attributes. The experiment followed a learning-to-learn model where on a series of six trials Ss were asked to learn categorized lists of words where the items and the categories were different for each list. In fact, the only thing the lists had in common was that they were composed of 25 words, five each from five different categories. An increase in recall would be taken to indicate that $\mathrm{Ss}$ had learned a "rule" that was appropriate to the task (and, as a matter of fact, overcome possible deleterious retroactive-inhibition effects). It was further reasoned that acquisition of this rule would be easier for words chosen from among those most frequently given as a member of a category than for words lower in the hierarchy of category members. Consequently, three sets of lists were prepared, varying the frequency of occurrence of the list items in the categories chosen.

\section{SUBJECTS}

The Ss used were 75 male and female undergraduate psychology students at the University of Colorado Denver Center.

\section{MATERIALS}

Six stimulus lists were prepared at each of the three "frequency" levels. Each list was made up of 25 words, five words from each of five categories, taken from the norms prepared by Battig \& Montague (1968). Words qualified for high-frequency (HF) lists if they were among the first seven members of a given category. Medium-frequency (MF) lists were composed of items taken from the midrange of the response distributions, and low-frequency (LF) lists were composed of items from among the last seven responses given to category names. Within each frequency level stimulus items appeared only once. The same category was used only once within frequency levels.

\section{PROCEDURE}

Each $S$ was read a stimulus list twice through at a rate of one word every $2 \mathrm{sec}$ and was then asked to write down as many of the words from the list as he could recall in any order. After an allowance of $3 \mathrm{~min}$ to record recall, a second list was read twice and recall was again written. This procedure continued without pause until the $\mathrm{S}$ had heard and recalled six lists. As Ss reported to the experiment, they were assigned to a frequency level for the lists they were to hear. The lists were read in a different random order for each of the Ss. Thus, performance over trials was a within-S variable; frequency of occurrence of list items was a between-S variable. Ss were assigned such that there were $25 \mathrm{Ss}$ for each of the three frequency levels.

\section{RESULTS}

The recall data are presented graphically in Fig. 1. The important thing to keep in mind about Fig. 1 is that the trials do not represent the same lists for all $\mathrm{Ss}$, even within frequency levels. The between-frequency differences were significant $(F=20.41, \quad d f=2 / 72$. $\mathrm{p}<.001)$. For all frequency levels there was increased recall as a function of the order of presentation of the lists $(F=24.68 . d f=5 / 360 . p<.001)$. There was also a significant interaction effect $(F=7.28, \quad d f=10 / 360, \quad p<.01) . \quad$ This 


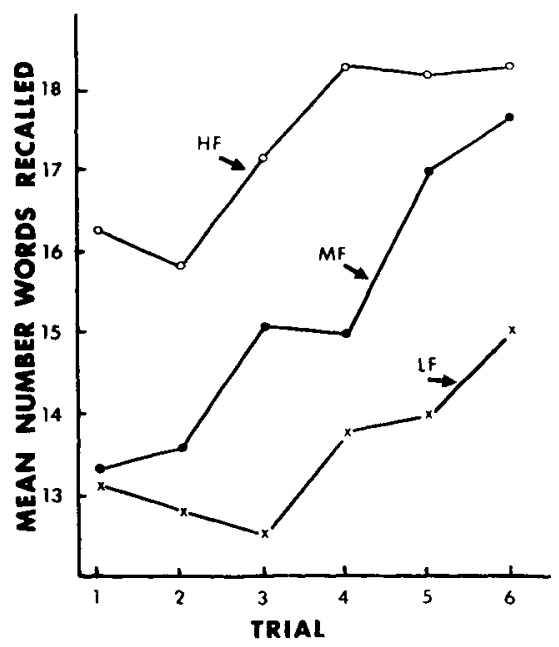

Fig. 1. Mean number of words recalled as a function of the order of trials for the groups receiving high-frequency (HF), medium-frequency (MF), and low-frequency (LF) lists.

interaction reflects the fact that the group of Ss using the low-frequency lists did not begin to show an increase in performance until the fourth trial.

Figure 2 presents the data on average cluster size over trials and frequency levels. A cluster was defined as a sequence of two or more items of the same category; hence, the possible range of average cluster size is 1.00 to 5.00 for five-item categories. Again, the data reveal a significant frequency-level effect $(F=27.81$, $\mathrm{df}=2 / 72, \quad \mathrm{p}<.001), \quad$ an increased performance over trials $(F=20.44$, $\mathrm{df}=5 / 360, \mathrm{p}<.001)$, and interaction $(F=3.64, \quad \mathrm{df}=10 / 360, \quad p<.05)$. Obviously, the meaning of the interaction in this case is less,clear than it is for the recall data, reflecting the large increase in cluster size at and after four trials for the group of Ss learning LF lists. The correlation between total recall and average cluster size over all Ss was +.559 .

\section{DISCUSSION}

The results of this experiment have a number of important implications concerning the "rules" of recall. Ss learned to use the attribute of category membership in recalling stimulus lists. Each trial involved a completely new set of stimulus words. The Ss never saw the same word twice, nor did they experience the same category twice. As noted above, the only thing the six lists had in common was the fact that they were made up of words from five categories. It seems reasonable, then, to assume that the increase in performance that occurred as a function of practice was due to a formulation of a best strategy to be used in the process of recall. Ss learned the best way to go about doing what the E wanted.

Interitem or category name-item associations could have had nothing to do with the observed increases in performance over trials. If the formation of associations across lists should have had any effect on subsequent recall it should have been to depress performance due to some type of retroactive interference (Shuell, 1968). The differences in performance as a function of the frequency of the list items can be readily handled in terms of response availability or increased probabilities of association formation.

We know that telling Ss the actual categories to be used in a categorized free-recall experiment increases performance. We know that simply telling Ss that the list can be categorized increases performance. The experiment reported here indicates that $S s$ can learn this information themselves, that they can learn the rules to maximize their performance. This general rule of how to proceed, or what to look for, has nothing to do with whatever associative networks might be inherent in the stimulus lists learned.

\section{REFERENCES}

BATTIG, W. F., \& MONTAGUE, W. E. Category

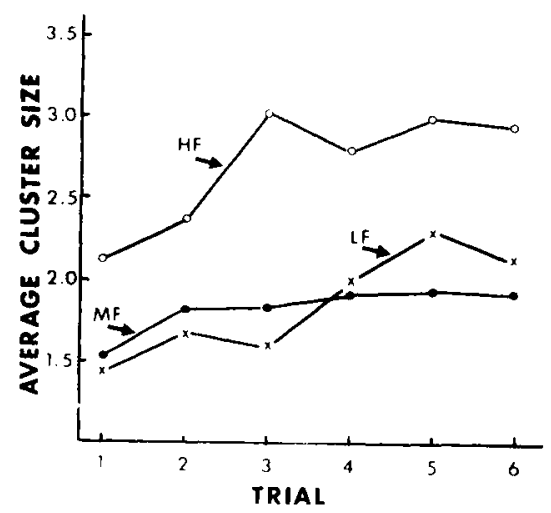

Fig. 2. Average cluster size as a function of the order of trials for the groups receiving high-frequency (HF), medium-frequency (MF), and low-frequency (LF) lists.

norms for verbal items in 56 categories. Technical Report, University of Colorado, August 1968.

HUDSON, R. L. Supplementary report: Category clustering as a function of level of information and number of stimulus presentations. Journal of Verbal Learning \& Verbal Behavior, 1968 , 7, 1106-1108.

JENKINS, J. J., \& RUSSELL, W. A. Associative clustering during recall. Journal of Abnormal \& Social Psychology, 1952, 47, 818-821.

MANDLER, G. Association and organization: Facts, fancies and theories. In T. Dixon and D. L. Horton (Eds.), Verbal behavior and general behavior theory. Englewood Cliffs, N.J: Prentice-Hall, 1968. Pp. 109-119.

POLLIO, H. R., \& GEROW, J. R. The role of rules in recall. American Joumal of Psychology, 1968, 81, 303-313.

SHUELL, T. J. Retroactive inhibition in free-recall learning of categorized lists. Journal of Verbal Learning \& Verbal Behavior, 1968, 7, 797-805.

TULVING, E. Subjective organization in free recall of "unrelated" words. Psychological Review, 1962, 69, 344-354.

UNDERWOOD, B. J. Attributes of memory. Psychological Review, 1969, 76, 559-573. 